\title{
К ВОПРОСУ О НАРУШЕНИИ ПРИНЦИПА СОСТЯЗАТЕЛЬНОСТИ СТОРОН В УГОЛОВНОМ ПРОЦЕССЕ
}

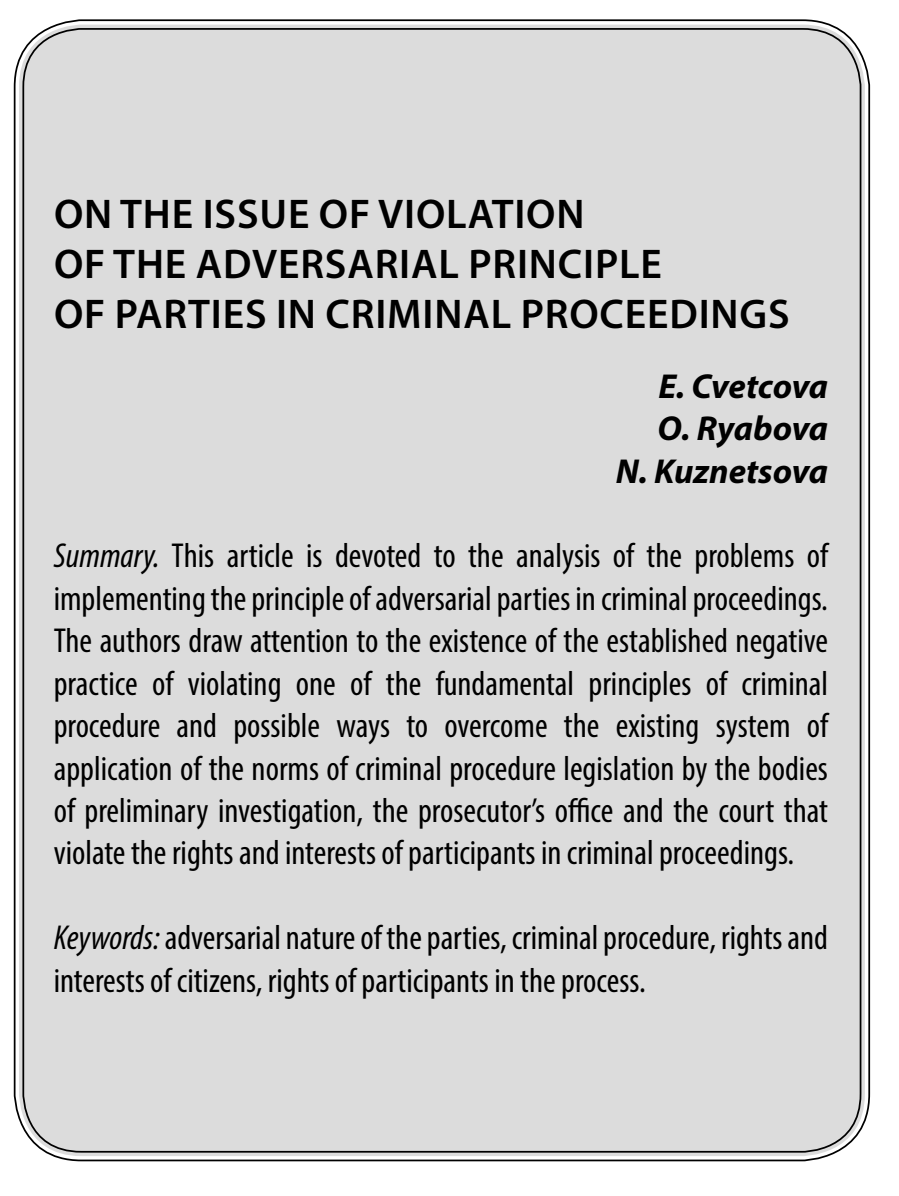

C остязательность сторон является одним из основных принципов уголовного процесса применительно ко всем его стадиям. Данный принцип закреплен в уголовно-процессуальном законодательстве Российской Федерации.[2] Нарушение указанного принципа должно становиться основанием для недоверия выводам предварительного следствия, органам прокурорского надзора и судебного разбирательства и, как следствие, вынесенному судебному акту.

Вследствие этого изучение и анализ практической реализации указанного принципа на всех стадиях уголовного процесса является одним из актуальных и приоритетных направлений на сегодняшний день.

Несоблюдение принципа состязательности сторон нередко приводит к нарушению прав участников уголовного процесса в ходе предварительного расследования и при последующем рассмотрении уголовного дела в суде.

\author{
Цветкова Елена Владимировна \\ К.ю.н., доцент, Владимирский Государственный \\ Университет имени Александра Григорьевича и Николая \\ Григорьевича Столетовых \\ cvetcova-e@mail.ru \\ Рябова Ольга Алексеевна \\ Преподаватель, ФКОУВО «Владимирский \\ юридический институт ФСИН России» \\ frau.lelya2012@yandex.ru \\ Кузнецова Наталья Владимировна \\ Старший преподаватель, ФКОУ ВО «Владимирский \\ юридический институт ФСИН России» \\ kuznezova-1963@mail.ru
}

Аннотация. Настоящая статья посвящена анализу проблем реализации принципа состязательности сторон в уголовном процессе. Авторы обращают внимание на наличие сложившейся негативной практики нарушения одного из основополагающих принципов уголовного процесса и возможные пути преодоления сложившейся системы применения норм уголовного процессуального законодательства органами предварительного расследования, прокуратуры и судом, нарушающим права и интересы участников уголовного производства.

Ключевые слова: состязательность сторон, уголовный процесс, права и интересы граждан, права участников процесса.

Любое производство по уголовному делу ставит своей целью установление фактических обстоятельств, правовая оценка которых сможет обеспечить его участникам надежду на принятие обоснованного и законного процессуального решения по нему. Такие обстоятельства представляют собой события или явления, произошедшие в прошлом, которые требуют объективного установления. Перечень таких обстоятельств - общий как для досудебного, так и для судебного производства по делу.

Установление всех фактических данных при производстве по делу и их анализ связаны с процессом познания человека и его мышлением, определяют отношение участников уголовного процесса к предмету доказывания по уголовному делу и, впоследствии, к оценке полученных доказательств. Все доказательства, основанные на установленных фактических данных должны соответствовать требованиям, установленным уголовным и уголовно-процессуальным законодательством. 
Оценка выясненных обстоятельств и выводы предварительного расследования находят свое отражение в постановлении о привлечении лица в качестве обвиняемого. В соответствии с уголовным законодательством Российской Федерации обвинением по уголовному делу является совокупность вменяемых в вину факторов, которые содержат состав квалифицируемого преступления, фактическую основу которого и образуют обстоятельства, отражающие юридическую суть преступного деяния необходимость доказывания которых обусловлена сущностью уголовного судопроизводства в целом.

Анализ исполнения органами предварительного следствия (дознания) требований уголовного и уголовно-процессуального законодательства нередко свидетельствует о том, что гарантии государственной защиты конституционных прав граждан на доступ к правосудию и судебную защиту не всегда обеспечиваются надлежащим образом, а действующие механизмы ведомственного контроля не оказывают должного влияния на реализацию одной из главных целей уголовного судопроизводства - принятие законного решения.

Сотрудниками правоохранительных органов, осуществляющими предварительное расследование, зачастую на системной основе допускаются нарушения требований федерального законодательства на досудебных стадиях уголовного процесса, что лишает его участников реальной возможности реализации своих процессуальных прав на данной стадии разбирательства, а также влечет за собой нарушение конституционных прав и законных интересов граждан на доступ к правосудию, защиту их прав со стороны государства.

Несмотря на провозглашение принципа состязательности, стадии предварительного расследования в российском уголовном процессе все же характерен так называемый «обвинительный уклон».

В связи с этим необходимо понимать, что при существующем положении попытка восстановления нарушенных прав участников уголовного процесса, к сожалению если и возможна, то только уже на стадии судебного разбирательства.

Следует отметить, что указанная органом предварительного расследования в итоговом процессуальном документе по уголовному делу квалификация содеянного является «предварительной», в то время как окончательная же юридическая оценка деяния реализуется исключительно судом.

Однако зачастую на практике даже установление судом фактов нарушения прав участников уголовного процесса на стадии предварительного расследования не приводит к изменению ранее предъявленного обвинения, а тем более вынесению оправдательного приговора.

Обвинительный уклон, к сожалению, не является исключением и при разрешении дела в суде. Вынесение оправдательного приговора отрицательно сказывается на деятельности правоприменителя. В связи с этим весьма показательно высказывание Чупилкина Ю.Б.: «Оправдание подсудимого имеет негативные последствия для всей правоохранительной системы» [4]. В таких случаях, вместо оправдания подсудимого, судья пытается найти решение, удовлетворяющее обе стороны, заручившись поддержкой вышестоящей инстанции.

Возникают сомнения в эффективности реализации принципа состязательности при разрешении дела судом, поскольку попытки исправления судом ошибок органов предварительного расследования в интересах в первую очередь потерпевших в рамках публичных правоотношений, не вполне отвечают истинным целям правосудия. В этом контексте приобретают важное значение слова «рассудить» и «осудить». Учитывая тот факт, что суд должен рассудить и сделать вывод о виновности того или иного лица на основании собранных предварительным следствием доказательств, судьи зачастую разрешают вопрос не о виновности или невиновности, а о том, насколько тяжкое наказание применить для подсудимого, заранее предполагая о виновности лица. При таком положении дел принцип состязательности не работает, и, например, защитник подсудимого, может повлиять только на размер наказания, даже заведомо понимая, что вина лица не доказана, предоставив при этом все доказательства невиновности своего подзащитного. Судья, получая дело, видит некачественную работу следствия и органов надзора в лице прокуратуры, но исправить их вынесением оправдательного приговора суд себе позволить не может.

Конституционный Суд РФ отмечает, что «не может рассматриваться как принятие на себя судом не свойственной ему функции обвинения вынесение решения, направленного на исправление допущенных органами, осуществляющими уголовное преследование, нарушений или ошибок, которые могут затрагивать интересы как обвиняемых, так и потерпевших, - иное вынуждало бы его принять решение, заведомо противоречащее закону, что в принципе недопустимо».[5] Необходимо помнить, что должная квалификация работников следствия и прокуратуры дают возможность судам получать качественные с точки зрения процессуального и материального права уголовные дела для дальнейшего рассмотрения в суде и правосудие не должно страдать от отсутствия квалификации некоторых работников следствия и надзорного органа.[5] 
С данным мнением нельзя не согласиться. Так в случае, если при разрешении дела суд, придя к выводу о несоответствии предъявленного обвинения фактическим обстоятельствам произошедшего, в том числе ввиду неправильной квалификации инкриминируемого подсудимому деяния, либо, если будут установлены фактические обстоятельства, являющиеся основанием для предъявления обвинения в совершении более тяжкого преступления, в том числе при наступлении более тяжких последствий, вправе возвратить уголовное дело прокурору для исправления указанных противоречий, предотвратив вынесение заведомо незаконного решения.

Вместе с тем, Азаров В.А, и Нурбаев Д.М., описывая допустимость поворота к худшему при возврате уголовного дела прокурору, утверждают: «Конституционный Суд РФ подчеркивает, что невозможность переквалифицировать действия подсудимого ставит решение суда в зависимость от квалификации, принятой органами уголовного преследования, а это - неправомерное вмешательство в осуществление судебной власти, самостоятельность и независимость которой находятся под защитой Конституции Российской Федерации».[7]

В общем понимании изменения ранее предъявленного обвинения можно разделить на две группы. Суть первой заключается в том, что в ходе судебного производства по уголовному делу устанавливаются обстоятельства, которые улучшают положение обвиняемого. Так, например, следователем направлено в суд уголовное дело по обвинению М. в хищении имущества П., совершенном с причинением последнему значительного ущерба, то есть в совершении преступления, предусмотренного п. «В» ч. 2 ст. 158 УК РФ. Вместе с этим, в ходе судебного следствия потерпевший заявил о том, что материальный ущерб, причиненный преступным действием М., не является значительным для него и членом его семьи. Данное обстоятельство в ходе предварительного следствия не изучалось. Факт значительности ущерба подтверждения в ходе судебного заседания не нашел.

Таким образом, по квалифицирующему признаку значительности причиненного ущерба лицо оправдывается, и у государственного обвинителя имеются основания для изменения квалификации инкриминируемого М. преступления на ч. 1 ст. 158 УК РФ.

Судом выполнены требования ч. 2 ст. 252 УПК РФ, положение подсудимого улучшено (изменена категория преступлений в соответствии по ст. 15 УК РФ), при этом право потерпевшей стороны на защиту не нарушено.

Ко второй группе относятся случаи, которые предполагают ухудшение положения обвиняемого, связанные с внесенными в обвинительный акт изменениями и дополнениями, которые в той ли иной мере ухудшат положение последнего.

Это может выражаться, во-первых, в увеличении числа инкриминируемых эпизодов преступной деятельности, во-вторых, в изменении квалификации в сторону усиления ответственности, то есть в совершении более тяжкого преступления, предусмотренного Особенной частью УК РФ, в-третьих, наоборот, в увеличении размера ущерба, причиненного преступлением, в-четвертых, наступление новых, более тяжких последствий преступного деяния и т.д.

Указанные положения являются основанием возвращения уголовного дела судом прокурору в порядке п. 6 ч. 1 ст. 237 УПК РФ.

Современные тенденции, ориентирующие законодателя на внедрение принципа состязательности в уголовное судопроизводство, затрагивают в том числе и вопросы ухудшения положения подсудимого. Кроме этого, попытки законодателя внедрить указанные нормы вызывают ряд проблем, связанных с их реализацией.

В первую очередь ввиду остро обозначившейся проблемы возможности ухудшения положения подсудимого при реализации судом своих полномочий, предусмотренных ст. 237 УПК РФ, институт, регламентированный данной нормой, невозможно признать наиболее оптимальным средством разрешения таких проблем.

Кроме этого, слабая правовая регламентация и неоднозначные, отчасти противоречивые разъяснения Конституционного Суда РФ относительно механизмов его реализации, также свидетельствуют о его неэффективности в существующей правовой системе современности.

Суд не может осуществлять уголовное преследование. Однако, по нашему мнению, возвращая уголовное дело прокурору для возможно ужесточения объема обвинения, он невольно становится участником со стороны обвинения.

Государство в лице суда обязано рассматривать представленные и исследованные доказательства в том виде, в котором они были переданы органами предварительного следствия, предполагая, что доказательная база собрана в полном объеме, а если указанных доказательств недостаточно для признания вины подсудимого, то суд обязан выносить оправдательный приговор.[6]

Обратим внимание, что в соответствии с ч. 3 ст. 15 УПК РФ суд создает необходимые условия для исполнения 
и осуществления сторонами, предоставленных им в соответствии с законодательством прав и обязанностей.

Суд, осуществляя правосудие, руководствуясь основными федеральными законами при рассмотрении находящегося в его производстве уголовного дела, не ориентируясь и не занимая позицию какой-либо из сторон, самостоятельно оценивает обстоятельства произошедшего и выносит справедливое решение, при этом, гарантируя реализацию прав всех участников уголовного судопроизводства.

Вместе с тем в соответствии с ч. 1.3 ст. 237 УПК РФ суд, возвращая по соответствующим основаниям уголовное дело, указывает на обстоятельства, которые явились основанием для возможной квалификации действий обвиняемого по более тяжкому преступлению, но не указывает на квалификацию и не дает оценку доказательств. Однако, при изучении постановления суда орган предварительного расследования зачастую воспринимает постановление суда как своеобразное указание и руководство по квалификации действий обвиняемого по более тяжкой статье, чем была предъявлена ранее, сбору доказательств виновности лица, вынесении нового постановления о привлечении в качестве обвиняемого, выполнении необходимых следственных и процессуальных действий и направлению вновь уголовного дела прокурору для решения вопроса в порядке ст. 220 УПК РФ. При этом, несомненно, право обвиняемого на защиту нарушается. Соответственно, прокурор, изучив решение суда, соглашается с новой квалификацией, утверждает обвинительное заключение направляет дела в суд. По сути правоприменители «идут» по пути наименьшего сопротивления, полагая, поскольку окончательное решение принимает суд, то необходимо «выполнять» его «указания».

Таким образом, анализ вышеперечисленных обстоятельств позволяет сделать вывод о том, что существенным фактором, мешающим осуществлению провозглашенного законодателем принципа состязательности сторон, а, следовательно, и правосудия в России, являются именно следственные ошибки, которые являются объективно существующей реальностью.

В связи с этим, как одной из актуальных задач, представляется необходимость совершенствования существующих процессуальных мер реализации института возвращения уголовного дела для производства дополнительного расследования в целях обеспечения недопущения нарушения прав, свобод и законных интересов участников уголовного процесса.

Кроме этого, не исчерпаны возможности совершенствования одного из процессуальных механизмов исправления ошибок органов предварительного расследования, выступающих объективным препятствием к разрешению дела судом, на досудебной стадии уголовного производства, которым является прокурорский надзор, закрепленный в п. 15 ч. 1 ст. 37, п. 2 ч. 1 ст. 221 УПК РФ, то есть направление уголовного дела прокурором следователю (дознавателю) для производства дополнительного следствия (дознания) и устранения выявленных недостатков со своими письменными указаниями.

Прокуратура фактически исполняет на протяжении длительного времени функцию обеспечения защиты прав и свобод личности от допускаемых нарушений сотрудниками правоохранительных органов.

Органы прокуратуры, осуществляя надзор за соблюдением Конституции РФ и исполнением законов, действующих на территории страны, обязаны своевременно реагировать на любые нарушения положений и норм уголовного и уголовно-процессуального законодательства, влекущие ущемление законных прав, свобод и интересов граждан и организаций в ходе расследования уголовных дел, поскольку предотвращение риска вынесения неправосудных решений, является важнейшим условием для нормального функционирования государства в целом.

Если прокурор утвердил итоговый документ, вынесенный следователем или дознавателем при окончании стадии предварительного расследования, следовательно, он соглашается с квалификацией содеянного, объемом предъявленного обвинения и собранными по делу доказательствами. Именно эту позицию он должен отстоять в суде в рамках состязательности сторон. В противном случае, прокурор может воспользоваться своими правами, предоставленными ему уголовным процессуальным законодательством.[2] Если в судебном заседании прокурор не может поддержать обвинение, по сути утвержденное им же, то он вправе отказаться от его поддержания на основании ч. 7 ст. 246 УПК РФ.

Для достижения указанной цели и решения проблем, носящих межотраслевой характер, необходимо законодательно закрепить положение о необходимости принятия прокурором решения об обоснованности предъявленного обвинения в рамках расследуемого уголовного дела и в последующем во время утверждения обвинительного заключения (акта, постановления) с обязательным отражением отсутствия нарушений, мешающих разрешению судом дела по существу, установленных ст. 237 УПК РФ, а также об установлении персональной ответственности прокурора за принятие такого решения.

Таким образом, выявленные проблемы являются серьезным поводом для анализа, направленного на исправление создавшегося положение дел. Учитывая, что 
рассмотрение любого уголовного дела и результат такого рассмотрения является судьбоносным для его участников, законодателю, возможно, необходимо обратить внимание на тему реальной ответственности за нарушение фундаментальных принципов уголовного производства, к которым относится принцип состязательности сторон. Такие нарушения напрямую связаны с нарушением законных прав и интересов гражданина. Процесс оптимальной реализации указанного принципа должен стать важной предпосылкой для проведения в России судебной реформы и дальнейшего процесса построения правового государства.

\section{ЛИТЕРАТУРА}

1. Конституция Российской Федерации (принята всенародным голосованием 12 декабря 1993 года) // Российская газета. 25.12.1993 г. № 237

2. Уголовно — процессуальный кодекс РФ от 18 декабря 2001 г. // Российская газета от 22 декабря 2001 г. № 249

3. Обзор практики Верховного Суда РФ № 2 (2018) (утв. Президиумом Верховного Суда РФ 4 июля 2018 г.) // Бюллетень Верховного Суда Российской Федерации, март 2019, № 3, апрель 2019, № 4

4. Чупилкин Ю.Б. Как разорвать «0бвинительную связку» между судом и правоохранительными органами? // Адвокатская практика. 2016. № 3. с. 53-56

5. Колоколов Н.А. Обвиняет суд? // Российский судья. 2016. № 5. с. 40-45.

6. Шелухина Е.В. Ухудшение положения обвиняемого при возвращении судами уголовного дела прокурору// Вестник современных исследований. 2020. № 1. C. 23-25.

7. Азаров В.А., Нурбаев 0 допустимости ухудшения положения обвиняемого (подсудимого) в контексте правовых позиций Конституционного суда России // Законы России: опыт, анализ, практика, 2016, № 4, с. 8

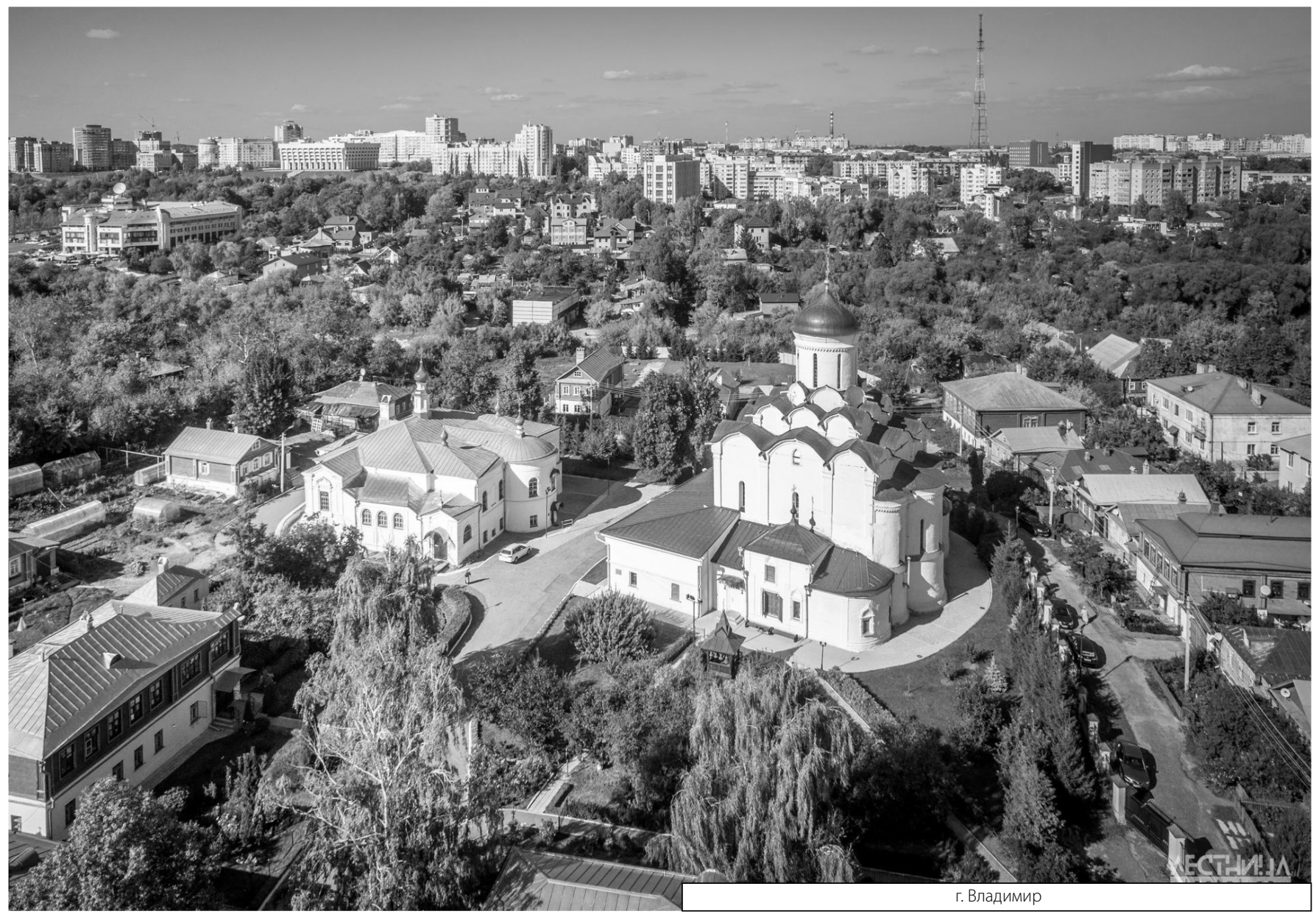

